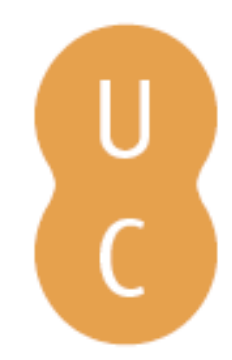

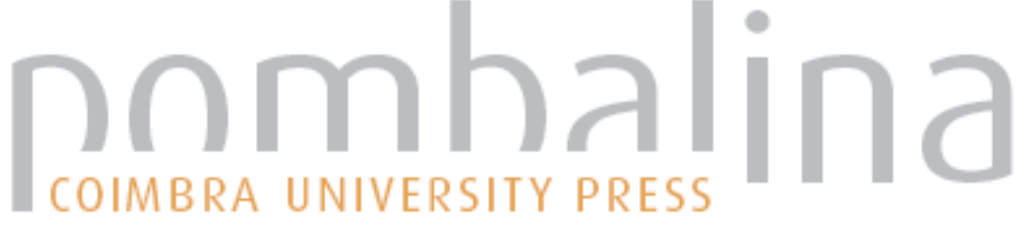

O Brasil na Universidade de Coimbra: um diálogo de geografias

Autor(es): $\quad$ Cunha, Lúcio; Jacinto, Rui

Publicado por: Imprensa da Universidade de Coimbra

URL

persistente: URI:http://hdl.handle.net/10316.2/30712

DOI: $\quad$ DOI:http://dx.doi.org/10.14195/978-989-26-0308-7_5

Accessed : $\quad$ 26-Apr-2023 13:41:57

A navegação consulta e descarregamento dos títulos inseridos nas Bibliotecas Digitais UC Digitalis, UC Pombalina e UC Impactum, pressupõem a aceitação plena e sem reservas dos Termos e Condições de Uso destas Bibliotecas Digitais, disponíveis em https://digitalis.uc.pt/pt-pt/termos.

Conforme exposto nos referidos Termos e Condições de Uso, o descarregamento de títulos de acesso restrito requer uma licença válida de autorização devendo o utilizador aceder ao(s) documento(s) a partir de um endereço de IP da instituição detentora da supramencionada licença.

Ao utilizador é apenas permitido o descarregamento para uso pessoal, pelo que o emprego do(s) título(s) descarregado(s) para outro fim, designadamente comercial, carece de autorização do respetivo autor ou editor da obra.

Na medida em que todas as obras da UC Digitalis se encontram protegidas pelo Código do Direito de Autor e Direitos Conexos e demais legislação aplicável, toda a cópia, parcial ou total, deste documento, nos casos em que é legalmente admitida, deverá conter ou fazer-se acompanhar por este aviso.

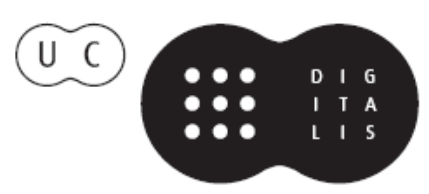



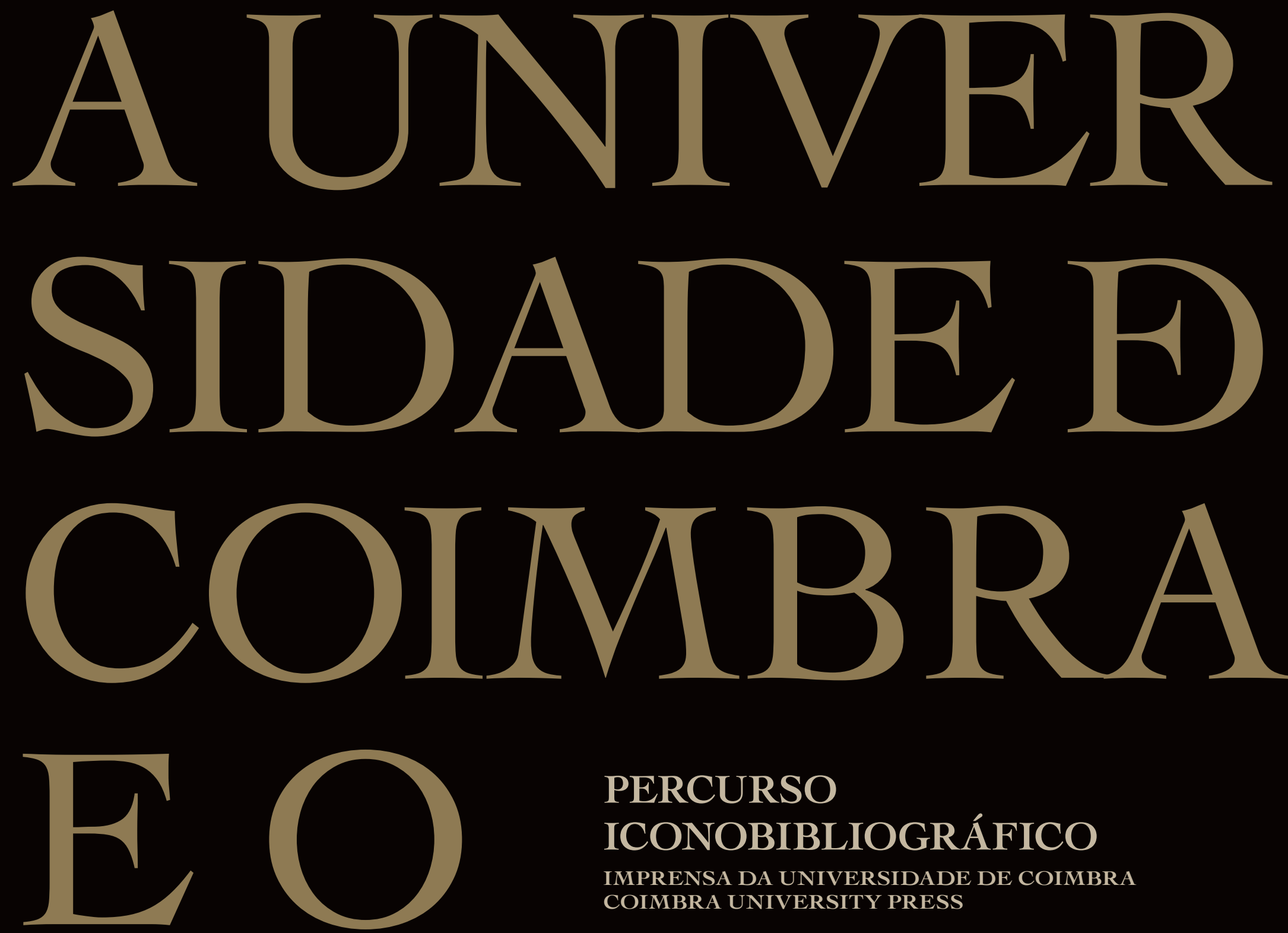

\section{PERCURSO}

\section{ICONOBIBLIOGRÁFICO}

IMPRENSA DA UNIVERSIDADE DE COIMBRA

COIMBRA UNIVERSITY PRESS

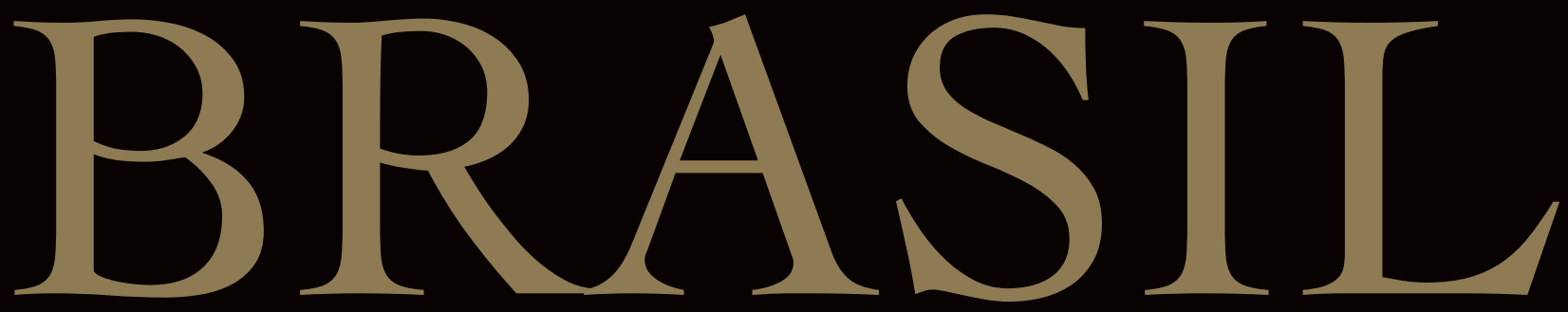


EDIÇÃO

Imprensa da Universidade de Coimbra

EMAIL: IMPRENSAUC@CI.UC.PT

URL: HTTP://WWW.UC.PT/IMPRENSA_UC

VENDAS ONLINE: HTTP://WWW.LIVRARIADAIMPRENSA.COM

Coordenação Científica

José Pedro Paiva

José Augusto Cardoso Bernardes

Textos

Joño Gabriel Silva

José Pedro Paiva

José Augusto Cardoso Bernardes

Joaquim Romero Magalhães

Décio Ruivo Martins

Fernando Ramos

Lúcio CunHa

Rui JaCINTO

JoÃo Arriscado Nunes

Maria Aparecida Ribeiro

Investigação e Conteúdos das Fichas Catalográficas

A.E. Maia do Amaral (Bguc)

Ana Maria Leitão Bandeira (auc)

Créditos Fotográficos

Miguel Pacheco/Redinteg Lda. (Digitalizações de livros e documentos)

Gilberto Pereira (exemplares zoológicos)

Pedro Casaleiro (exemplar etnográfico)

Tiago Maia/AuC (PeÇas museológicas - Ma)

Delfim Ferreira (arquitetura)

DESIGN

António Barros

INFOGRAFIA

Carlos Costa

EXECUÇÃo GRÁFICA

NORPRINT

ISBN

978-989-26-0161-8

Depósito Legal

Obra Publicada com o Patrocínio de 

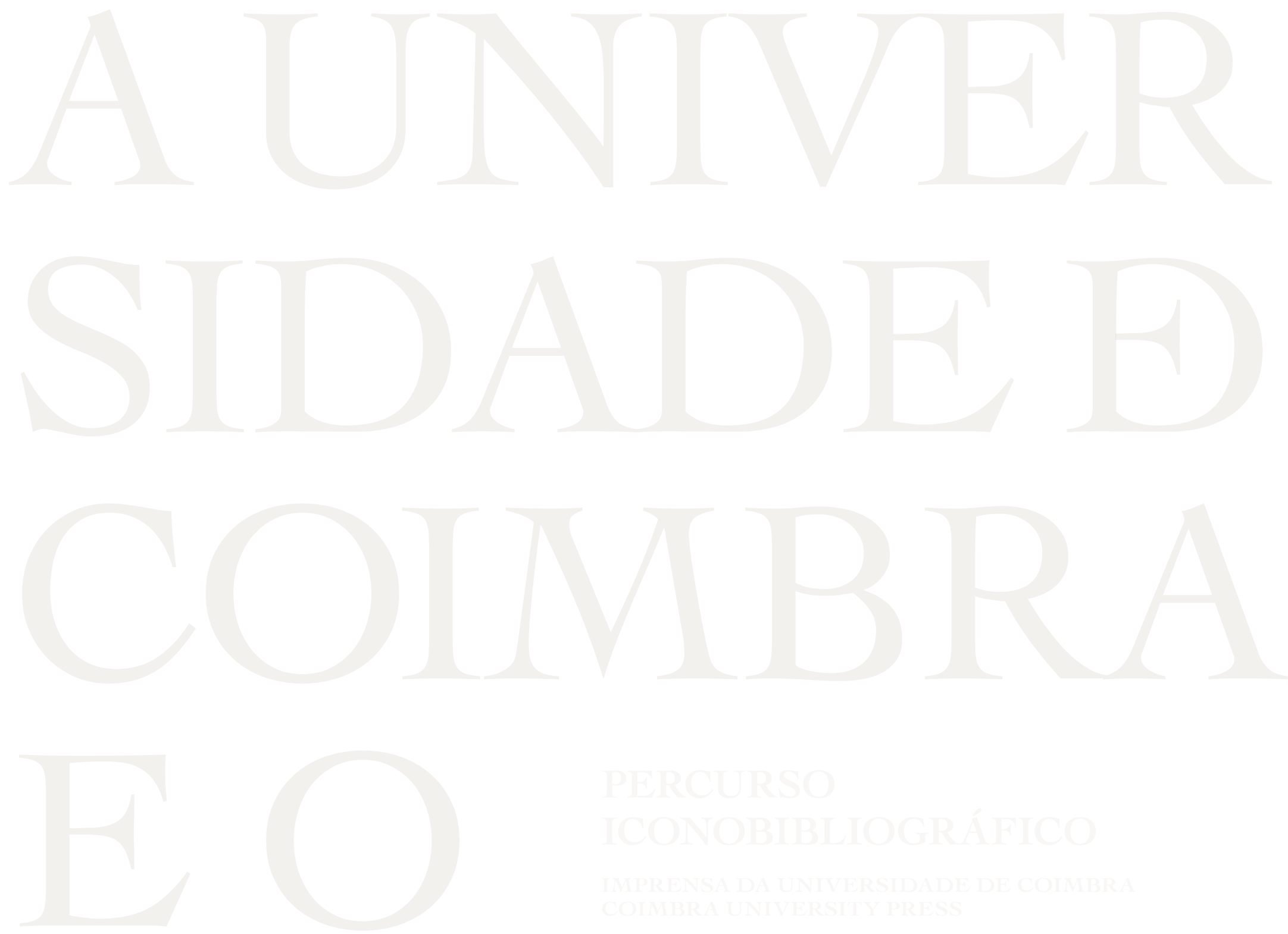

PRTOUROO
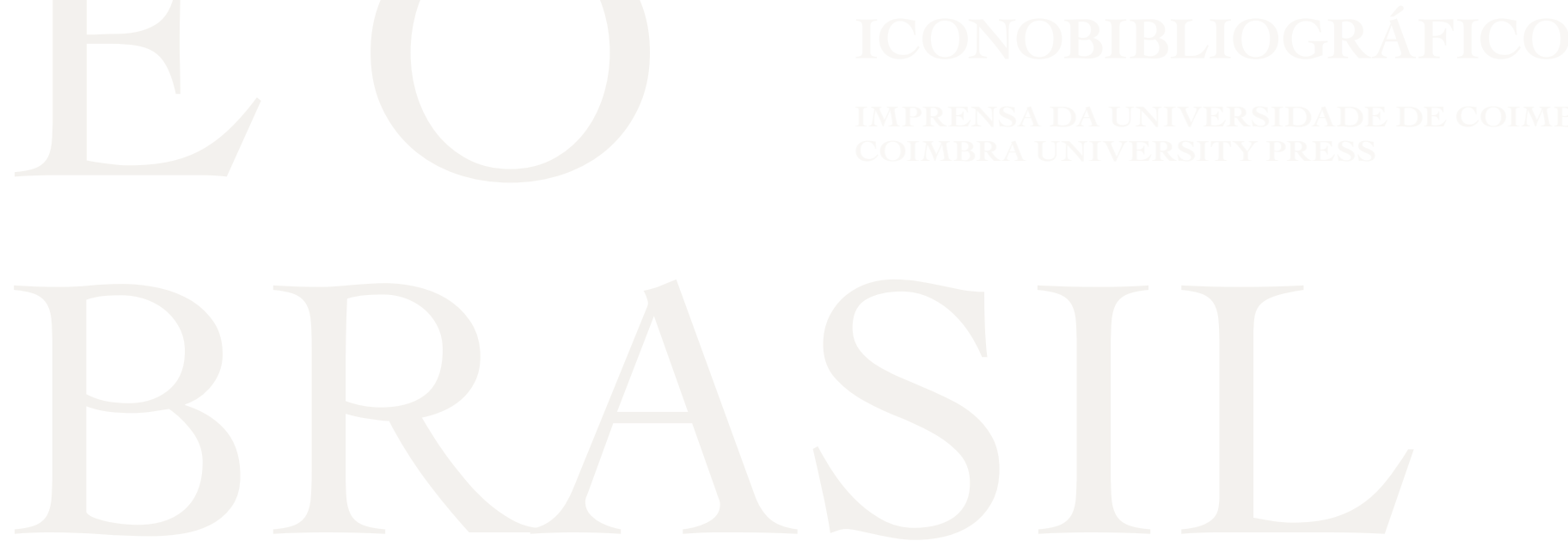
(Página deixada propositadamente em branco) 


\title{
O Brasil na Universidade De Coimbra Um diálogo de Geografias
}

\author{
Lúcio Cunba
}

Rui Jacinto 



\section{A}

presente reflexão sobre a importância e o papel do Brasil na Universidade de Coimbra,

particularmente na área científica da Geografia, implica uma análise retrospetiva do relacionamento entre a investigação geográfica que se foi produzindo no Brasil e em Portugal, perceber os pontos de contacto e de interação que se foram estabelecendo e entender o modo como se articulam e interagem as redes entretanto constituídas. Esta reflexão parece-nos muito importante para perspetivar o modo de construção de um futuro de cooperação, desenvolvimento e enriquecimento da Universidade de Coimbra e, no seu seio, da área científica de Geografia.

$\mathrm{Na}$ análise que se apresenta, necessariamente breve e, também por isso, de algum modo injusta, distinguem-se, com alguma facilidade, três períodos ou fases: a primeira corresponde basicamente à primeira metade do século XX e constitui a fase de construção do pensamento geográfico nos dois países, com contactos ainda tímidos e relativamente pouco frutuosos; a segunda corresponde às décadas de sessenta a noventa do século passado e constitui o período de afirmação da ciência nos dois países, ainda que marcado pelo divórcio no relacionamento entre as suas Geografias; finalmente, a partir dos anos 90, inicia-se uma fase de intenso relacionamento, diálogo e cooperação, baseada na criação de redes que promovem a investigação conjunta, o intercâmbio de alunos e professores e que, de algum modo, contribui para a afirmação das geografias portuguesa e brasileira nos quadros mais gerais da lusofonia e do mundo ibero-americano.

1. Geografias em construção: um diálogo incompleto dos geógrafos pioneiros

Tanto em Portugal como no Brasil o desenvolvimento da Geografia enquanto ciência autónoma, embora possa vir claramente de trás e, em especial, do século XIX, faz-se sobretudo durante o século XX. No nosso país, e na nossa Universidade, os estudos universitários de Geografia surgiram, formalmente com a criação das Faculdades de Letras em 1911 (Oliveira, 2003; Rebelo, 2003) ${ }^{1}$. Iniciados pela mão de Anselmo Ferraz de Carvalho, vão passar quase vinte anos até à constituição formal de uma secção de Estudos Geográficos, ou seja até à institucionalização efetiva da Geografia como unidade científica autónoma, institucionalização que conheceu também um lento processo de afirmação a que estão ligados os nomes de Aristides de Amorim Girão, Virgílio Taborda, Orlando Ribeiro e Alfredo Fernandes Martins. No Brasil, essa institucionalização terá sido ligeiramente mais tardia, com a criação dos cursos de Geografia e de História e com a constituição do Instituto Brasileiro de Geografia e Estatística (IBGE) e da Associação dos Geógrafos Brasileiros (AGB), fundada por Pierre Deffontaines, na segunda metade da década de 30 , a que se seguiu uma fase de intensa preparação internacional, quer em França, quer nos Estados Unidos, que rapidamente proporcionou à Geografia brasileira um lugar de destaque no panorama internacional ${ }^{23}$.

1 OLIVEIRA, J. M. P. (2003) - "Da evolução dos estudos geográficos na Universidade de Coimbra”. In ALMEIDA, A.C., GAMA, A., CRAVIDÃO, F.D., CUNHA, L. e JACINTO, R. - Fragmentos de um retrato inacabado. A Geografia de Coimbra e as metamorfoses de um país. Coimbra, pp. 23-31.

Rebelo, Fernando (2003) - "A investigação geográfica em Coimbra". In ALMEIDA, A.C., GAMA, A., CRAVIDÃO, F.D., CUNHA, L. e JACINTO, R. - Fragmentos de um retrato inacabado. A Geografia de Coimbra e as metamorfoses de um país. Coimbra, pp. 33-41.

2 LIMA, Miguel Alves (2003) - Os anos dourados da Geografia Brasileira: antecedentes, realizações e consequências dos anos 50 e 60. Revista Geo-paisagem, 3. (http://feth.ggf.br/Revista3.htm; consultado em 6 de janeiro de 2012).

3 - MElo, Adriany A., VLACH, Vânia R. F. e SAMPAiO, Antóno C. F. "História da geografia escolar brasileira: continuando a discussão". Disponível em: http://www.faced.ufu.br/colubhe06/anais/arquivos/239AdrianyMelo_VaniaRubia. pdf (consultado em 6 de janeiro de 2012). 
Durante muitos anos, poderíamos dizer que quase até ao final do século XX, o Brasil, ainda que sempre presente na Geografia portuguesa, sobretudo em termos didáticos, nas aulas sobre os diferentes aspetos da natureza nos espaços tropicais, sobre geografia política global e regional ou, ainda, sobre Geografia de Portugal, ao abordar, por exemplo, os temas de emigração, andou arredado da investigação geográfica na nossa Universidade.

No entanto, algumas exceções são dignas de referência e alguns trabalhos publicados nos anos 40 e 50 do século passado na Revista do Instituto de Estudos Brasileiros da Faculdade de Letras, a Brasilia, dão conta das preocupações científicas e da importância que a jovem Geografia coimbrã atribuía aos espaços geográficos brasileiros. Merece uma referência especial o trabalho de A. Fernandes Martins sobre a Borracha brasileira (1946) ${ }^{4}$, um estudo pioneiro em Portugal sobre Geografia Económica do Brasil, em que o autor reflete acerca dos efeitos da evolução geopolítica global para justificar, o forte impacto na economia amazónica provocada pela concorrência das produções na África, primeiro, na Malásia e na Insulíndia, depois, durante as primeiras décadas do século XX. O autor refere-se também à evolução da geopolítica da borracha durante a Segunda Guerra Mundial, anunciando o que considerava ser o renovar das possibilidades económicas para a borracha brasileira e para o seu território de eleição, a Amazónia. A sua reflexão premonitória constitui uma importante chamada de atenção para a importância geoestratégica da produção de matérias-primas, designadamente as extrativas e as alimentares, que vieram dar um impulso enorme à economia brasileira nas últimas décadas, como acontece com a produção

4 MARTins, Alfredo Fernandes (1946) - "Grandeza, declínio e novas possibilidades da borracha brasileira”. Brasilia, Coimbra, III, pp. 341-376. de soja, açúcar ou gado, mas também de petróleo ou de minérios de diferentes tipos, para citar apenas os exemplos principais.

No mesmo número da Revista Brasilia podemos encontrar outro texto do autor com o título "Geografia Humana do Brasil" e que corresponde a interessante e muito bem contextualizada recensão da palestra proferida na altura, no Instituto de Estudos Brasileiros da Faculdade de Letras da Universidade de Coimbra, por Pierre Deffontaines ${ }^{5}$, e que ilustra a forte influência francófona nas geografias dos dois países lusófonos.

Ainda no mesmo número da Brasília, é possível encontrar um interessante artigo de Anselmo Ferraz de Carvalho ${ }^{6}$ em que o autor, numa perspetiva de enaltecimento da colonização portuguesa, utiliza os elementos físicos e, particularmente, a geologia para estabelecer comparações e confrontos entre os territórios do Brasil e de Angola no que diz respeito às suas potencialidades de desenvolvimento: "um novo Brasil na forma simples por que Angola se apresentava a tantos portugueses" (p. 143).

Finalmente, merece também uma atenção especial o trabalho de Geografia Política escrito por A. Amorim Girão para a mesma revista sobre o papel de "Portugal e o Brasil no Mundo de amanhã" ${ }^{7}$. Assumindo o discurso do regime, a expansão portuguesa é um tema caro ao autor que, num texto de forte pendor ideológico, debate o papel e a importância da língua de Camões, ou seja, de Portugal, entendido como estado colonial e pluricontinental, e do Brasil, como o maior país de expressão portuguesa, num mundo cada vez mais pequeno face ao "encurtamento das

5 MARTins, Alfredo Fernandes (1946) - "Geografia Humana do Brasil". Brasilia, Coimbra, III, pp. 809-824.

6 CARVAlhO, Anselmo Ferraz (1946) - "Angola, pequeno Brasil". Brasília, Coimbra, III, pp. 141-148.

7 GIRÃO, Aristides de Amorim (1952) - "Portugal e o Brasil no Mundo de amanhã”. Brasília, Coimbra, VII, pp. 19-33. 
distâncias pela aceleração dos meios de transporte". Perspetiva "uma nova organização transnacional baseada na comunidade de sangue, de língua e de religião, de tradição e de costumes" e cita Gilberto Freyre que a ela se refere como "essa pátria maior, que é a unidade cultural formada pelas várias expressões do esforço português espalhadas sobre o mundo moderno e a tão grandes distâncias umas das outras”. Para a sua Geografia Humana $^{8}$ (1946), Amorim Girão tinha já desenhado um mapa extremamente interessante que aponta para o Brasil a lista de topónimos portugueses, dando assim conta da influência de Portugal no processo de construção do território brasileiro (fig. 87 - Reflexo toponímico da colonização portuguesa do Brasil, p. 312; reproduzida no Atlas de Portugal, III - Portugal e os portugueses no Mundo de hoje) ${ }^{9}$.

Podem apontar-se os autores citados como pioneiros no diálogo entre a Geografia dos dois países, uma relação que abria janelas, ainda que estreitas, para conhecimento geográfico do Brasil e que seria mais afetiva que real, numa altura em que as viagens não eram fáceis. Mesmo assim, Alfredo Fernandes Martins ainda teve oportunidade de se deslocar a Salvador da Bahía, em 1959, numa missão que hoje é recordada nessa Universidade, se bem que não tenham sobrado resultados concretos em termos de colaboração institucional.

2. Afirmação das Geografias Portuguesa e Brasileira: um período de adormecimento

Os anos sessenta, setenta e oitenta do século passado foram, verdadeiramente, o tempo de afirmação da ciência geográfica em Portugal e no Brasil. Entre nós, particularmente na Universidade de Coimbra, nos anos sessenta o conhecimento dos espaços tropicais passava muito mais por missões e trabalhos de campo

8 GIRÃO, Aristides de Amorim (1946) - Geografia Humana. Portucalense Editora, Porto, 383 p.

9 GIRÃO, Aristides de Amorim (1958) - Atlas de Portugal (2 ${ }^{\text {a }}$ edição). Instituto de Estudos Geográficos, Coimbra nas colónias ultramarinas do que por uma articulação efetiva com o país de economia emergente que era já o Brasil.

O tempo que se seguiu à Revolução dos Cravos foi um tempo de reestruturação, primeiro, de crescimento, depois, para chegar, só nos anos oitenta, a um tempo de relacionamento da Geografia de Coimbra com as Geografias Ibérica, Europeia e Global, mas de que o relacionamento com o Brasil ficou um tanto arredado.

Não significa isso que não houvesse alguma influência teórica da Geografia brasileira nos estudos que entretanto se faziam em Coimbra. Muitos dos conhecimentos, teorias e metodologias novas chegavam-nos mais facilmente, por causa da língua, através do Brasil. Num tempo em que se operava uma clara viragem da influência da Geografia escrita em francês para a Geografia anglófona, de uma Geografia dita clássica de sabor qualitativo para a chamada Nova Geografia marcadamente quantitativa, as obras de eminentes geógrafos brasileiros como Josué de Castro, Milton Santos, Azis Ab Saber, António Christofoletti ou Carlos Augusto Monteiro, para citar apenas os mais conhecidos, continuam a chegar-nos e a integrar as listas bibliográficas de muitas teses e artigos publicados em Coimbra sobre os mais diversos temas geográficos.

3. Desenvolvimentos recentes (o reencontro das geografias portuguesa e brasileira)

A partir dos finais do século passado, mais exatamente dos anos 90, assiste-se ao reencontro das Geografias de Portugal e do Brasil. Condições políticas, económicas e culturais do lado de cá e do lado de lá do Atlântico ditaram uma aproximação que, no caso da Universidade de Coimbra, está a ser marcada por um intercâmbio crescente de professores e alunos, pela realização de reuniões científicas conjuntas e por um crescendo de publicações que dá visibilidade internacional às Geografias dos dois países. A esta fase estão claramente ligados os nomes de Fernando Rebelo e de José Manuel Pereira de Oliveira.

Como vimos, ainda que com altos e baixos, desde sempre, a Universidade de Coimbra deu particular atenção às relações 
institucionais com Universidades brasileiras. Mas terá sido com Fernando Rebelo enquanto Reitor (1998-2002) que estas relações atingiram o seu auge ou que, pelo menos, foram catapultadas para esta nova e mais intensa fase de relacionamento institucional.

Geógrafo, Professor e Reitor da Universidade de Coimbra, Fernando Rebelo visitou o Brasil pela primeira vez em 1996, em viagem particular. Seguiram-se muitas mais viagens, pelo menos uma dezena, de caráter privado ou oficial. Nelas participou em reuniões de trabalho em mais de 20 universidades, proferiu conferências ${ }^{10}$ e participou em trabalhos de campo. Em consequência deste frutuoso conjunto de atividades, foram escritas crónicas de viagem, depois compiladas em livro ${ }^{11}$ que dão conta, quer das diferentes geografias encontradas nos itinerários percorridos, quer das relações institucionais criadas. Aquelas repartem-se por todo o Brasil e a sua leitura permite a compreensão de realidades naturais tão distintas como a Amazónia, o Pantanal ou a costa do Rio de Janeiro, as vicissitudes de crescimento urbano em S. Paulo, Rio de Janeiro ou Brasília e o modo como, um pouco por todos os recantos do Brasil, se encontra um pouco de Portugal, na arquitetura, nos costumes e na religião. Estas têm a sua expressão maior na criação do Grupo de Coimbra de Universidades Brasileiras (GCUB), um grupo de 50 universidades brasileiras "universidades nacionais - federais, estaduais, confessionais e comunitárias - que reconhecem a instituição conimbricense como alma mater" 12 , formalmente constituído em Coimbra, no ano de 2008, mas cuja ideia nasce com a chamada "Carta de S. Paulo" assinada em 2001, por ocasião da visita do Magnífico Reitor à Universidade Presbiteriana MacKenzie.

10 Estas conferências versaram diferentes temas que vão desde o Sistema Universitário Português e a Universidade de Coimbra até temas científicos ligados à História da Geografia (USP e UEBA), aos Riscos (ditos) Naturais (UNICAMP e UFBA) e às relações entre a Geografia e o Turismo (UNIFACS e UNICAMP).

11 REBELO, Fernando (2006) - Viagens pelo Brasil. Impressões de um geógrafo. Memórias de um reitor. Minerva Coimbra, $191 \mathrm{p}$.

12 Sítio na Internet do Grupo de Coimbra das Universidades Brasileiras: http:// www.grupocoimbra.org.br/coimbra/index.php (acedido em 6 de janeiro de 2011)
Outra parte importante do relacionamento da Geografia de Coimbra com a Geografia brasileira faz-se através dos muitos professores brasileiros que Fernando Rebelo convidou para os Encontros sobre Riscos Naturais Urbanos, depois Encontros sobre Riscos Naturais e, finalmente, Encontros Nacionais de Riscos, após a constituição da Riscos, Associação Portuguesa de Riscos, Prevenção e Segurança, em dezembro de 2003. Muitas destas contribuições ficaram registadas em importantes artigos na Revista Territorium de que Fernando Rebelo foi o criador e, desde o momento da criação em 1994, Diretor. Só no último número desta revista $\left(\mathrm{n}^{\circ} 17,2010\right)$ são pelo menos 10 os trabalhos apresentados por especialistas brasileiros, alguns em colaboração com geógrafos portugueses, o que muito diz acerca do aprofundamento das relações científicas entre a Geografia dos dois países lusófonos. $\mathrm{Na}$ impossibilidade de referir todas as participações brasileiras havidas na Territorium, mas ante a necessidade de justiça no que se refere à importância desta participação, destacam-se, a título de exemplo, os trabalhos de alguns especialistas mais conhecidos ou reconhecidos internacionalmente na área da Geografia Física e dos Riscos Naturais, como os de Jurandyr Ross ${ }^{13}$, António Bueno Conti ${ }^{14}$ e António Carlos Vitte ${ }^{15}$.

Muitos outros contactos de geógrafos da Universidade de Coimbra portugueses com a realidade geográfica brasileira começaram pela mão de Fernando Rebelo, desenvolvendo-se de seguida de modo autónomo. Uma referência, uma vez mais a título de exemplo, para a bolsa de curta duração de pós-doutoramento de

13 ROSS, Jurandyr (2001) - "Inundações e deslizamentos em São Paulo. Riscos da relação inadequada sociedade-natureza”. Territorium, Coimbra, 8, pp. 15-24.

14 CONTI, António Bueno (2002) - "Riscos Naturais na Região Tropical Brasileira”. Territorium, Coimbra, 9, pp. 117-122.

15 VITTE, António Carlos (2003) - O litoral brasileiro: a valorização do espaço e os riscos sócio-ambientais. Territorium, Coimbra, 10, pp. 61-67

VITTE, António Carlos e FILHO Luís Ribeiro Vilela (2006) - "A urbanização, a fragilidade potencial do relevo e a produção do risco na bacia hidrográfica do Córrego Proença, Município de Campinas, Brasil”. Territorium, Coimbra, 13, pp. 105-114.

VitTE, António Carlos e MELlO, Juliano Pereira (2009) - "Determinação da fragilidade ambiental na bacia do rio Verde, região nordeste do Estado de São Paulo (Brasil)”. Territorium, Coimbra, 16, pp. 79-98. 
António Campar de Almeida, patrocinada pela Fundação Calouste Gulbenkian e que lhe permitiu, em 2005, visitar a Universidade de Campinas. Aí contactou os Professores António Carlos Vitte, Archimedes Perez Filho e Claudette Vitte, proferiu conferências (na Universidade de São Paulo; em Bauru e em Campinas) e, sobretudo, fez trabalho de campo para aprofundar o seu conhecimento sobre temas de análise da paisagem, biogeografia e dinâmica litoral (Campinas; Floresta Nacional de Ipanema, em Araçoiaba da Serra; litoral a sul do Estado de S. Paulo; Bauru; Rio Claro).

Outra importante fonte de articulação da Universidade de Coimbra com a Geografia brasileira está no Projeto GEOIDE, Geografia, Investigação para o Desenvolvimento. Este teve início numa ação do Programa ALFA, financiada pela União Europeia que, sob a coordenação de José Manuel Doutor Pereira de Oliveira, envolveu também universidades espanholas, francesas, inglesas, peruanas, mexicanas e brasileiras (1996-98).

Findo o período de vigência formal do programa financiado, aproveitaram-se e desenvolveram-se as relações entretanto criadas num projeto de algum modo informal que tem vindo a crescer através da convergência e mesmo da cumplicidade de interesses de geógrafos portugueses (da Universidade de Coimbra) e brasileiros (inicialmente da Universidade Estadual Paulista - UNESP - e que se foi alargando progressivamente a outras universidades ${ }^{16}$ ), mas também de outros países que falam português (Cabo Verde, Moçambique, Angola) e a que se juntam ainda colegas espanhóis que partilham connosco o seu interesse e a sua afeição pela Geografia falada em português. Trata-se de uma colaboração e de uma partilha de experiências de trabalho em espaços física e ambientalmente distintos, com diferenças paisagísticas e territoriais bem marcadas, com distintos problemas de desenvolvimento, mas tendo como base uma Geografia que se pretende moderna, rigorosa e, sobretudo, comprometida com as questões ambientais e com a coesão económica, social e territorial, ou seja com as regras que promovem o chamado "desenvolvimento sustentável”.

16 Maringá, Maranhão, Salvador da Bahía, Três Lagoas.
Tendo em conta os interesses teóricos e as áreas de trabalho dos protagonistas, o projeto desenvolve-se em torno de quatro grandes eixos temáticos:

1. Biodiversidade, paisagens, recursos, riscos e sustentabilidade: aproveitamento, gestão e ordenamento dos espaços naturais;

2. Espaços rurais, povoamento e processos migratórios;

3. Cidade e território: processos de urbanização e práticas sócio-espaciais;

4. Sociedades, culturas e mudanças: políticas públicas, valorização e reestruturação dos territórios.

No seu âmbito foram sendo desenvolvidas iniciativas diversas que incluem convites para trabalho de campo e trocas de conferencistas entre as Universidades de Coimbra e de Salamanca, por um lado, e a UNESP (Campus de Presidente Prudente), por outro, a par com a realização de vários seminários ${ }^{17}$ internacionais que permitiram formalizar a troca de experiências, fixar em textos publicados alguns dos avanços investigativos produzidos e ajudar a estabelecer uma rede que permita passar de um projeto informal para um "fórum permanente de estudo e debate que lance as bases para um observatório sobre as dinâmicas socioeconómicas e os processos de reestruturação territorial nos países de língua portuguesa"18. De algum modo, podem enquadrar-se também no

17 De entre os seminários científicos destacam-se no Brasil: S. Luís do Maranhão (Universidade Estadual do Maranhão - 2009 - I Colóquio Internacional sobre Desenvolvimento Local e Sustentabilidade, e 2011 - II Colóquio Internacional sobre Desenvolvimento e sustentabilidade - novas abordagens, velhos dilemas); em Presidente Pudente (Universidade Estadual Paulista - 2010 - Seminário Internacional sobre Meio Ambiente e Desenvolvimento: os países de língua portuguesa e as suas geografias: território e mudança em diferentes contextos regionais) e em Salvador da Baía (2011 - Universidade Federal da Baía Seminário Ibero-Brasileiro sobre Território e Desenvolvimento em Portugal e Espanha). Em Portugal realizaram-se seminários na Guarda, organizado pelo Centro de Estudos Ibéricos (2009 - Seminário Internacional “Os países de língua portuguesa e as suas geografias: dinâmicas socioeconómicas e processos de reestruturação territorial) e na Universidade de Coimbra (2010 - Encontros de geógrafos do língua portuguesa - As novas Geografias dos países de Língua Portuguesa: território e mudança em diferentes contextos regionais).

18 CUnhA, L. Passos, M. e JACINTO, R. (2010) - "Os países de língua portuguesa e as suas novas geografias”, In CUNHA, L. Passos, M. e JACINTO, 
âmbito deste projeto algumas viagens realizadas a Cabo Verde (2002; 2005; 2010; 2011) por investigadores da Universidade de Coimbra.

Parte do trabalho realizado tem já expressão formal em publicações, com destaque para o livro As novas geografias dos países de Língua Portuguesa. Paisagens, territórios, políticas no Brasil e em Portugal, editado pelo Centro de Estudos Ibéricos (CEI) e coordenado editorialmente por L. Cunha, M. M. dos Passos e Rui Jacinto (ob. cit.) que, organizado em torno de 3 grandes temas: 1) Paisagens, recursos, sustentabilidade; 2) Territórios, cidade e coesão urbana; e 3) Políticas públicas e reestruturação do território, inclui 22 trabalhos, dos quais 17 tratam a realidade brasileira. Neste momento está no prelo um segundo livro coordenado por Messias Modesto dos Passos e Rui Jacinto que incluirá textos de um conjunto de geógrafos da Universidade de Coimbra e da UNESP, mas também das Universidades de Cabo Verde e Eduardo Mondlane, em Moçambique. Começa a cumprir-se, assim, um dos objetivos do projeto Geoide, que é o de se alargar aos espaços geográficos da lusofonia.

Alguma institucionalização deste projeto foi conseguida com a sua aprovação pela CAPES (do lado brasileiro) e pela FCT (do lado português) ${ }^{19}$. Em funcionamento nos anos de 2011 e 2012, o projeto aponta como objetivo fundamental a estruturação de uma rede de investigação entre as Universidades de Coimbra e Estadual Paulista que funcione como embrião de uma rede mais ampla que envolva outras Universidades no Brasil e noutros países de expressão portuguesa. Deste modo ficaram reunidas condições materiais que permitem a deslocação de investigadores portugueses ao Brasil e de investigadores brasileiros a Portugal,

R. (2010) - As novas geografias dos países de Língua Portuguesa. Paisagens, Territórios, Políticas no Brasil e em Portugal. Iberografias, CEI, Guarda, 16, pp. 7-18. 19 Integram o projeto:

- pela Universidade de Coimbra, Fernanda Cravidão, Lúcio Cunha, Norberto Santos, António Campar de Almeida e Rui Jacinto;

- pela Universidade Estadual Paulista (UNESP, campus de Presidente Prudente), Messias Modesto dos Passos, Eliseu Spósito, Maria do Carmo Spósito, João Lima, Eda Goes; Nivaldo Espanhol; Rosangela Espanhol e Margarete Amorim. bem como um intercâmbio de estudantes de doutoramento que se está a revelar extremamente frutuoso ${ }^{20}$.

Recentemente, os cursos de Turismo da Faculdade de Letras foram integrados no Departamento de Geografia, num processo francamente enriquecedor para o Departamento e para o Grupo de docentes que o constituem. Parte significativa deste enriquecimento tem que ver com a dinâmica de relacionamento internacional, imposta por Fernanda Cravidão na coordenação destes cursos, e nomeadamente no que se refere ao Brasil. Sendo o turismo uma atividade, senão emergente pelo menos de desenvolvimento mais recente no Brasil que em Portugal, não admira que sejam muitos os estudantes da área que procuram os nossos cursos de pós-graduação. Assim acontece, quer com o curso de mestrado em Lazer, Património e Desenvolvimento, quer com o curso de doutoramento em Turismo, Lazer e Cultura (que envolve, além da Faculdade de Letras, a Faculdade de Ciências do Desporto e Educação Física) e que contam, entre os seus alunos, com um número significativo de estudantes brasileiros. O exemplo mais paradigmático desta procura, ou talvez melhor, deste relacionamento da Universidade de Coimbra com o Brasil, está num protocolo recentemente assinado entre a Universidade de Coimbra e o Serviço Social do Comércio (SESC) de Fortaleza, que permitiu a oito dos seus funcionários superiores frequentar o curso de doutoramento em Turismo, Lazer e Cultura e preparar, sob orientação de professores da Universidade de Coimbra, as respetivas dissertações.

A recente aproximação da Geografia e dos geógrafos portugueses e brasileiros tem tido também tradução nas reuniões de caráter internacional mais amplo em que participam, e, nomeadamente, naquelas que são organizadas em Portugal e no Brasil. Dois exemplos recentes são os Seminários Latino-Americanos de Geografia Física e as reuniões da União Geográfica Internacional (UGI).

20 No primeiro ano de funcionamento do projeto estagiaram em Coimbra três estudantes de doutoramento da UNESP e um estudante de Coimbra pôde fazer uma deslocação curta a S. Paulo. 
No que diz respeito à Geografia Física, uma importante articulação tem vindo a ser estabelecida entre as Geografias europeia e latino-americana através dos chamados Seminários Latino-Americanos de Geografia Física. Iniciados em La Habana (Cuba) no ano de 2000 e, depois, realizados bienalmente em Caracas, na Venezuela, em Puerto Vallarta, no México, em Maringá e em Santa Maria, no Brasil, e em Coimbra, no ano de 2010, está prevista a realização da edição deste ano de 2012 para Manaus. Trata-se de uma organização informal que foi congregando geógrafos de diferentes países da América Latina (Cuba, México, Argentina, Uruguai, Chile, Peru, Venezuela, Colômbia e Brasil) a que se juntaram portugueses e espanhóis, num processo de crescimento que, em 2008, no seminário de Santo Maria, levou à decisão de formalizar estes encontros como Seminários Ibero-Americanos, destinados a promover, também, a troca de experiências científicas entre as Geografias e os geógrafos dos dois lados do Atlântico. O VI Seminário (o II Seminário Ibero-americano) organizado em Coimbra, de 26 a 30 de maio de 2010, sob o lema "Sustentabilidade da Gaia: ambiente, ordenamento e desenvolvimento", foi o primeiro realizado fora do espaço da América Latina e terá sido, a maior reunião científica de geógrafos brasileiros fora do Brasil, já que foram cerca de 300 os geógrafos físicos do Brasil inscritos para apresentar mais de duas centenas de trabalhos, o que permitiu uma intensa troca experiências e importantes contactos para preparação de um futuro de cooperação científica. Cumprindo a curta tradição destes Seminários, num gesto que se revestiu de forte simbolismo para a Geografia Ibero-americana, foi prestada homenagem a dois destacados geógrafos de Portugal e Brasil: os Doutores Fernando Rebelo, da Universidade de Coimbra, e José Pereira de Queiroz Neto, da Universidade de São Paulo.

No que diz respeito a reuniões de UGI destacamos, pela participação ativa de Geógrafos de Coimbra, a reunião anual Commission on Evolving Issues of Geographical Marginality, subordinada ao tema geral Globalização e Marginalidade, que foi realizada na Universidade Federal de Rio Grande do Norte, em Natal, no ano de 2005, e de cuja relevância científica internacional dão conta os três volumes que reúnem os resultados da reunião ${ }^{21}$.

\section{Balanço prospetivo: Geografias, geógrafos e redes de cooperação}

Fruto desta aproximação são, neste momento, muitas as formas de cooperação pedagógica e científica entre a Geografia de Coimbra e a Geografia brasileira.

Por exemplo, a nível pedagógico, seja na graduação, no mestrado ou em doutoramento são muitos os estudantes brasileiros que procuram a Universidade de Coimbra, para realizar integralmente, ou tão só, para complementar a sua formação. Só em cursos de doutoramento de Geografia e de Turismo são mais de uma dezena os estudantes brasileiros que nos procuraram nos últimos 10 $\operatorname{anos}^{22}$. O inverso, ou seja a procura de universidades brasileiras por parte de geógrafos de Coimbra, também é verdadeiro, ainda que a dimensão do fenómeno seja bem menor. No entanto, aproveitando as facilidades da língua, as universidades brasileiras são procuradas também por estudantes de doutoramento portugueses, sobretudo no que diz respeito a bolsas de curtas duração para desenvolver competências nas áreas da Cartografia Automática, dos Sistemas de Informação Geográfica (SIG’s) e da Deteção Remota. Esta aproximação acaba por envolver professores de cá

21 1. Globalização e Marginalidade - Transformações Urbanas (2008). UFRN, $488 \mathrm{p}$.

Globalização e Marginalidade - O Rio Grande do Norte em foco (2008). UFRN, pp. 496-756

Globalização e Marginalidade - Desenvolvimento, na teoria e na prática (2008). UFRN, pp. 767-964.

22 Até ao momento foram já defendidas com êxito na Universidade de Coimbra duas dissertações de doutoramento de estudantes brasileiros, docentes na Universidade do Estado da Bahía:

SANTOS, Miguel Cerqueira (2008) - Turismo e ambientes costeiros. Os casos do Recôncavo Baiano e da Região Centro de Portugal. Diss. Doutoramento, Coimbra, 283 p. + anexos.

SANTOS, Maria Gonçalves Conceição (2008) - Um contributo para pensar a Geografia das Migrações. A comunidade brasileiras na Região Centro de Portugal. Diss. Doutoramento, Coimbra, 388 p.+ anexos. 
e de lá e, neste momento, esboçam-se algumas experiências de cotutoria que em breve darão frutos.

No plano científico, e como consequência das relações atrás referidas, há envolvimento de geógrafos da Universidade de Coimbra e de geógrafos brasileiros na realização de reuniões científicas internacionais, iniciam-se os seminários e cursos luso-brasileiros, multiplicam-se as conferências e cursos dados por geógrafos portugueses no Brasil e por geógrafos brasileiros em Coimbra, assim como se desenvolve o intercâmbio de investigadores pós-doutorados.

Hoje, importantes revistas brasileiras contam com geógrafos de Coimbra no seu corpo editorial: Mercator (Universidade federal do Ceará) ${ }^{23}$, Vivência (Universidade Federal do Rio Grande do Norte) ${ }^{24}$, Revista Espaço e Cultura (Universidade do Rio de Janeiro) ${ }^{25}$, Climep (UNESP, campus de Rio Claro) ${ }^{26}$. A nossa menor dimensão talvez justifique alguma falta de reciprocidade nos convites e, nas revistas da Geografia de Coimbra, apenas Jurandyr Ross (USP) consta como membro do Conselho Científico da Territorium.

No entanto, o CEGOT (Centro de Estudos de Geografia e de Ordenamento do Território) que agrega investigadores das Universidades de Coimbra, do Porto e do Minho, tem a honra de incluir o nome e de receber a avisada ajuda de Márcio Valença, da Universidade Federal do Rio Grande do Norte, enquanto membro da Comissão de Acompanhamento.

Em regra, os convites para integrar comissões científicas de unidades de investigação, de revistas ou de reuniões científicas, são apenas a tradução formal da prática de troca de experiências já realizadas. Como dissemos antes, esta prática é recente no que se refere ao intercâmbio das Geografias portuguesa e brasileira. Por isso também são poucos, ainda, os reflexos em termos de produção científica conjunta. São muitas e diversificadas

23 - Lúcio Cunha e Norberto Santos

24 - Fernanda Cravidão

25 - Fernanda Cravidão

26 - Lúcio Cunha as publicações de geógrafos brasileiros em Coimbra (Cadernos de Geografia ${ }^{27}$, Territorium, Atas do VISLAGF e em publicações de outras reuniões científicas realizadas em Coimbra, como o II Congresso Nacional de Geomorfologia, em 2004, e o VII Congresso da Geografia Portuguesa, em 2009). Serão, muito menos, mas igualmente diversificadas e importantes, as publicações de geógrafos de Coimbra em revistas de especialidade e livros de atas de reuniões científicas realizadas no Brasil. Mas, mais importantes e anunciadoras de um futuro de colaboração promissor são as publicações conjuntas que recentemente começaram a envolver colegas dos dois lados do Atlântico.

Fruto de condicionalismos históricos mais gerais ou das dinâmicas científicas e académicas específicas de cada um dos países, o relacionamento entre as Geografias de Portugal e Brasil, tem passado por fases de maior ou menos aproximação. O momento atual é de grande dinamismo neste relacionamento e a Universidade de Coimbra enriquece-se claramente com o intercâmbio de alunos, investigadores e docentes que se processa.

Para além das possibilidades de inserção em redes ibero-americanas e globais, as facilidades impostas por uma língua comum contribuem também para o relacionamento académico com outros países de expressão portuguesa. Até agora este relacionamento tem vindo a ser feito separadamente pelas Geografias portuguesa e brasileira. Com o projeto Geoide que temos vindo a desenvolver, iniciou-se já um trabalho de cooperação que envolve a Universidade de Cabo Verde e a Universidade Eduardo Mondlane, em Moçambique. Espera-se, para muito breve, poder estender o projeto a Universidades angolanas e, porventura, ainda que de modo mais pontual, também a $\mathrm{S}$. Tomé e a Timor.

27 Como atrás fizemos para a Revista Territorium, também apenas a título de exemplo, citam-se:

PASSOS, Messias Modesto (1998) - “A urbanização da fronteira agrícola na Amazónia Matogrossense”. Cadernos de Geografia, Coimbra, 17, pp. 175-185. VALENÇA, Márcio Moraes (2010) - "La Gioconda, a cidade contemporânea e os centros históricos”. Cadernos de Geografia, Coimbra, 29/29, pp. 151-158. 
As exigências de uma Universidade moderna, tanto em termos de docência como de investigação, apontam basicamente duas vias: trabalho em equipa e internacionalização. No que à segunda diz respeito, o relacionamento internacional, em particular com a Geografia anglófona, nomeadamente, através da publicação em consagradas revistas publicadas em língua inglesa com arbitragem e circulação internacionais, é fundamental para a afirmação da Geografia moderna que se faz na Universidade de Coimbra. Mas terá sempre de haver espaço para o Brasil, diríamos mesmo que é estratégico incrementar a cooperação com o Brasil e, através dela, desenvolver o espaço de Coimbra nas Geografias da lusofonia e do iberismo.

Em 1952, Amorim Girão citava Afrânio Peixoto: "Portugal-Brasil, unidos, reunidos, aliados, associados, económica, intelectual, moralmente. Isto será para o ano 2040... Mas queira Deus, seja antes“. Na altura faltavam quase 100 anos. Estamos agora, seguramente, mais perto de cumprir a profecia do pensador...

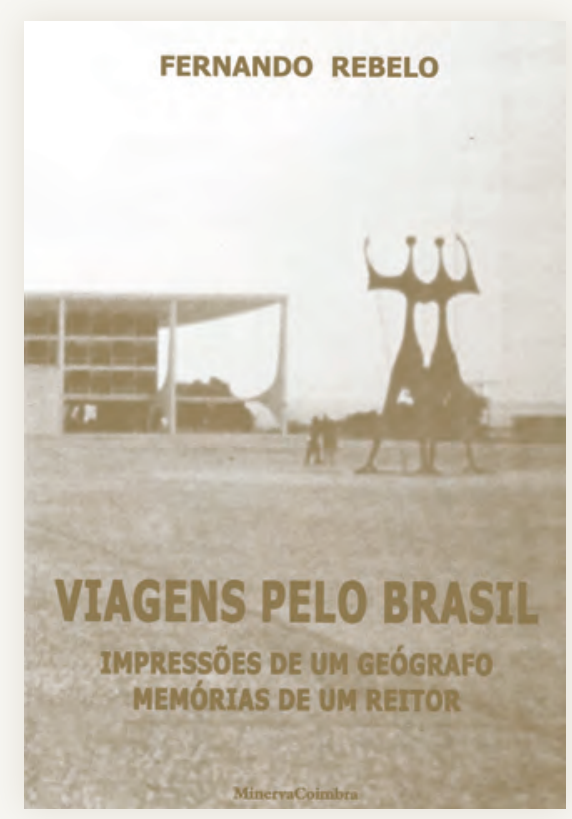

$$
\begin{gathered}
\text { Rebelo, Fernando, } 1943 \text { - } \quad \text { - Viagens pelo Brasil: } \\
\text { impressōes de um geógrafo memórias de um reitor. } \\
1^{\text {a }} \text { ed. Coimbra: Minerva Coimbra, } 2006 . \\
\text { BGUC: 8-(2)-22-2-60 }
\end{gathered}
$$

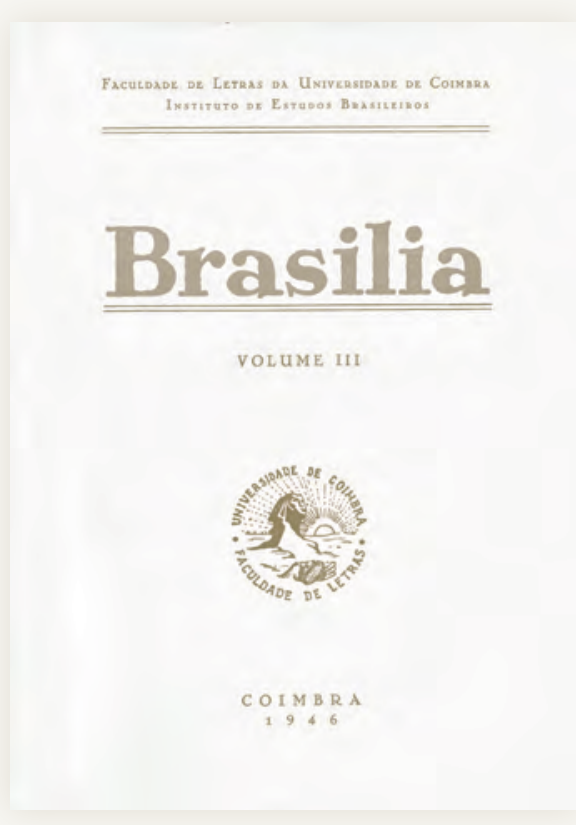

A revista "Brasília", publicação anual da Faculdade de Letras da Universidade de Coimbra dedicada aos estudos brasileiros. Capa do número 3 (1946). BGUC: A-1-56 
